\title{
Innovation and Practice in Teaching and Research of Programming Public Course Guided by the Construction of Service Specialty
}

\author{
Yizhen Liu \\ Liaoning Institute of Science and Technology \\ Benxi Liaoning China \\ lnbxlyz@126.com
}

\author{
Yinghui Wang \\ Liaoning Institute of Science and Technology \\ Benxi Liaoning China \\ 15998203039@163.com
}

\begin{abstract}
With the popularization and nationalization of higher education, the cultivation of applied and innovative undergraduate talents has become an issue of great concern to universities, employers and students. Based on the analysis of the current situation of the teaching of computer programming for applied undergraduates, we take the construction of service specialty as the main line, combine social needs and implement order-based Teaching for different majors of students. In order to break through the disadvantages of traditional teaching mode and take training applied talents as the ultimate goal, a reasonable innovative 135 teaching mode of public computer programing course has been constructed, and the students' comprehensive quality and comprehensive ability have been comprehensively trained and improved.
\end{abstract}

Keywords-Applied undergraduate; Service specialty construction; 135 innovative teaching mode

\section{INTRODUCTION}

With the popularization and nationalization of higher education, the cultivation of applied and innovative undergraduate talents has become an issue of great concern to universities, employers and students. At present, the public course of computer programming can't enable students to understand, learn and master from the scientific perspective of objectification in teaching mode, teaching content and teaching methods. However, the current public course of computer programming language can’t enable students to understand, learn and master from the scientific perspective of objectification in teaching mode, teaching content and teaching methods.

The information between teaching and learning is asymmetrical. Knowledge is more grasped by teachers, and information flow is basically one-way. The core standard of education quality is to see whether students have the spirit of innovation and practical ability. The challenge faced by the public course of computer programming language for applied undergraduate is how to train applied and innovative talents.

\section{A. Lack of advanced idea of practical teaching reform}

The traditional educational and teaching ideas are outdated and lack of ideas to meet the needs of social development and change. The students who were trained are often lack of practical ability. When combined with practical programming problems, they are mostly helpless. The pass rate of national computer grade examination is not very high too. The innovative consciousness and innovative thinking of the students trained are far from enough to meet the needs of contemporary society or the need of cultivating applied and innovative talents.

\section{B. Lack of scientific teaching mode in the common course of Computer Programming}

Programming course has been recognized as the basic content of undergraduate students in Colleges and universities to adapt to the development of the times. Its purpose is to cultivate students' ability to learn how to program and solve practical problems. The traditional teaching mode only pays attention to theoretical knowledge, but neglects the cultivation of students' practical ability. The teaching mode is teachercentered, and students passively accept knowledge, which hinders the transform of students mind called "one-way thinking" to "multi-way thinking", and does not create a favorable training space for students' application ability and innovation ability.

\section{Lack of teaching content in line with social needs and specialties}

The dullness of computer programming course content is a problem that all colleges and universities are facing in computer teaching. Most books are focused on theory and lack of practicality. Students are afraid of learning. In the whole teaching process, cases are mostly isolated and have no connection with each other. As a result, students' knowledge is scattered and unsystematic, students whose ability of practical innovation is weak, and teaching content and curriculum system can’t keep up with the rhythm of social development.

\section{Lack of flexible and pluralistic teaching methods and means}

Teaching quality is the lifeline of education, and the improvement of teaching quality is the basis for the survival and development of higher education. Only by strictly grasping quality management can higher education develop on a healthy track. Traditional teaching methods are single. Teachers in class pour various kinds of computer theory knowledge into 
students. After listening to the lecture for too long, students' attention in class drops obviously, which makes students feel dull and unintelligible. They have no motivation to learn, which seriously restricts the improvement of teaching quality and teaching effect.

\section{E. Lack of effective and standardized assessment system of practical teaching quality}

Course assessment is often the most important link for students. Most of the content of assessment focuses on theoretical knowledge, which is easy to give students the illusion of "emphasizing theory while neglecting practice". The goal of the teaching of computer programming course in universities is to improve and strengthen the logical thinking ability and practical programming ability of College students' computer programming. The assessment methods of computer programming language course in most colleges and universities limit students' ability and space of innovative thinking, and promote students to study dogmatically can't think deeply, analyze or solve problems independently.

\section{RESEARCH AND IMPLEMENTATION OF TEACHING} INNOVATION OF PUBLIC COURSE OF PROGRAMMING ORIENTED BY THE CONSTRUCTION OF SERVICE SPECIALTY

\section{A. Hold on the concept of "educating people first"}

Institutions of higher learning shoulder the mission of delivering high-quality talents for the country and society. People-oriented is the main content of the scientific development concept. Only by adhering to the educational concept of "educating people first" and cultivating the comprehensive quality of college students in an all-round way can the mission of training applied technical talents for the country and society be realized.

College students are the mainly force to realize the strategy of rejuvenating the country through science and education. Educating people is the basis of quality education and the premise of educational purposes and tasks. We should change our educational concept, adhere to the educational concept of "educating people first", take the development of students as the main line, guide and mobilize students' subjective initiative through the educational concept of "educating people first", and make clear "why to learning" and "how to learn" enable students to learn to learn, learn to think and cultivate their ability of lifelong learning, possess the knowledge structure and ability quality that can meet the needs of scientific and social development in the 21st century, and cultivate their subjective consciousness and learning concept of serving the country and society and realizing social and personal values.

\section{B. Breaking the drawbacks of traditional teaching mode,} construct 135 innovative teaching mode, and cultivate students' comprehensive quality and ability in an all-round way.

Construct 135 innovative teaching mode, that is, one center, three modules and five kinds of ability training. 1 refers to the development of college students as the center; 3 refers to the construction of service specialty under the guidance of mind map, and divides the teaching content into three teaching modules; 5 refers to the cultivation of students' self-learning ability, practical application ability, scientific and technological innovation ability, cooperative learning communication ability and organizational management ability. To strengthen the development of students as the center, focusing on the cultivation of scientific and cultural quality as the dominant, ideological and moral quality, physical and mental quality and professional quality as the assistance of the comprehensive quality of College students.135 teaching mode fully reflects that teachers are helpers and promoters of knowledge construction, not providers and inculcators of knowledge, students are the main body of information processing, active constructors of learning, rather than the object of individualized acceptors and inculcators of knowledge. The 135 teaching mode aims to optimize the teaching mode of the common course of computer programming language, focusing on the training of applied technical talents based on "serving professional construction and training skills for post".135 teaching mode is an innovative teaching mode centered on students' development and guided by cultivating students' comprehensive quality and ability. It conforms to the development trend of higher education in our country, meets the needs of society for applied technical talents, and speeds up the economic development and scientific and technological progress of our country.

\section{Taking the construction of service specialty as the main line, implementing order-based teaching according to social needs and different specialties}

Teaching strategy is an integral part of teaching design. It is a teaching plan and measures taken to achieve teaching objectives and meet students' learning needs in specific teaching situations[1]. Our teaching strategy is to take practicability, systematicness, compound and development as the direction of construction, take training applied technical talents as the goal, carry out modular integration of teaching contents, make teaching modules independent of each other, connect with each other according to knowledge system, improve the logic and cohesion of teaching contents, and run through the practical teaching and application of different majors all the time. In the process of learning, students are the main body, teaching according to their aptitude, and the construction of service specialty is the main line to make students apply what they have learned.

Combining with the demand of talents in the social market, optimizing and integrating modular teaching content with the goal of application, designing practical, innovative and indigenous teaching cases, following the principles of "learning while using, first using and then using, theoretical guidance and highlighting practice", and combining with the actual teaching situation of the common course of computer programming language in our school, designing and implementing suitable teaching cases for our schools' service specialty Build an innovative teaching module featuring Computer Culture Foundation + programming (VB, C, VF), and gradually cultivate students' basic programming ability, application ability and expansion ability. Based on the principles of practicability, systematicness, compound and development, we 
construct a modular teaching content model of VB programming language course, which takes the construction of service specialty as the main line and takes the application as the goal. As shown in Fig. 1.

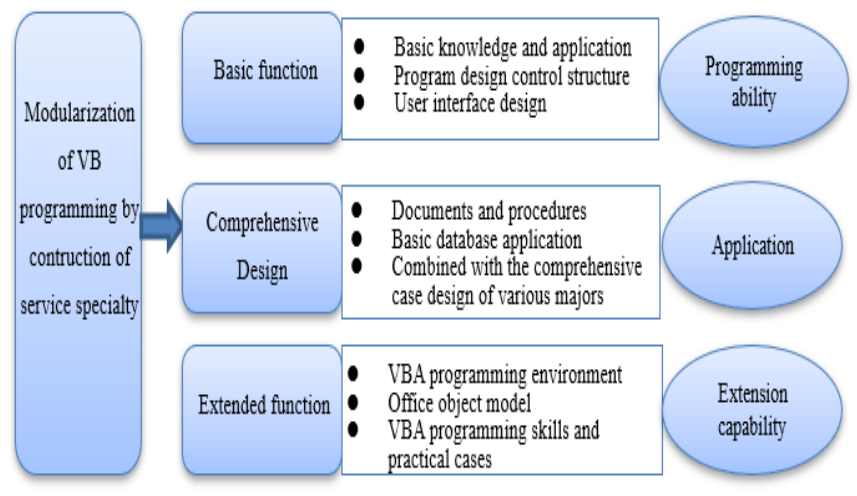

Fig. 1. VB Programming Modularization Teaching Content

Taking VB programming as an example, this paper clarifies the overall training objectives of each module, breaks the traditional knowledge-centered curriculum content system, cancels the restrictions of chapters, organically combines closely related theories and practical operations, and adopts the order-based case teaching in the integrated design module, which is guided by the construction of service specialty and combines different professional design cases. It not only strengthens the organic combination of professionalism and practicability, but also effectively solves the contradiction between the systematicness of subject system and the comprehensiveness of knowledge required by production practice, so as to make the teaching process purposeful, targeted and planned. Modular teaching not only takes into account the teaching of basic knowledge, but also highlights the pertinence of professional teaching, taking into account the unity of teaching plans as well as students. It has the autonomy of learning, avoids repetitive teaching of knowledge, implements modular information technology teaching for different majors, improves students' knowledge level and practical ability. Through modular teaching, students' learning ability assumes a ladder situation. To the greatest extent, students' theoretical knowledge and operational ability are greatly improved, and their mastery of knowledge and skills is more comprehensive and firm.

\section{Adopting scientific and diversified teaching methods to highlight the individuality of teaching style}

Computer programming language, because of its abstract concepts and more grammatical content and many other problems, students often give up in the learning process because of dullness and dullness. We regard Mind Mapping [2] as a new teaching strategy and adopt a diversified teaching method, which is mainly based on Mind Mapping and supplemented by PBL (Problem-Based Learning) and other mixed teaching methods. By using the teaching methods of interest and visual impact, we can apply them to the teaching of computer programming language, so that students can learn to learn, cultivate students' quality of divergent and innovative thinking, and further enhance their ability of analysis and problem solving. We can use mind mapping method to describe the obscure, abstract and hard-to-remember theoretical knowledge with mind mapping. It is simple, vivid and clear to describe the algorithm, structure and usage of various grammars in programming languages. It not only makes students easily understand the overall structure of grammar, but also deepens their memory, understanding and mastering the logical relationship between grammar and grammar. Make the teaching objectives specific and meticulous, so as to facilitate students' understanding, digestion and efficient learning. Taking VB programming as an example, we use mind mapping to design a teaching case and visualize the whole process of VB case design in front of students. It not only enables students to master the process of programming, but also cultivates and strengthens the idea of software engineering, which plays a key role in demonstrating students' learning of computer language design and integrating theory with practicing. Through the design of mind mapping teaching cases, students not only grasp the steps and methods of program design, but also strengthen the importance of curriculum practice. The monotonous imagedrawing thinking is transformed into a visualized and decentralized thinking teaching mode. While focusing on cultivating students' innovative and practical application abilities, students learn to sort out the overall thinking of the project and plan the overall project process. To clarify the objectives and operations of each step, to make the overall design of the project, detailed design and so on, scientifically and visually strengthen and cultivate students' computer software engineering ideas.[3]

Learning interest determines learning attitude, which directly affects learning effects. We adopt the classroom teaching method with mind mapping as the main method and PBL (problem-based learning method) as the supplement. Before class, Flipped Classroom and the second network classroom are combined as the method of pre-class preview. In the classroom, teachers and students interact through the combination of case guidance, questioning and work presentation. Activate the classroom atmosphere and arouse students' enthusiasm for learning. After class, students are divided into groups (according to the principle of dormitory or voluntary) to study, face-to-face teaching, network counseling, network ability testing, network homework and other mixed teaching methods to complete the overall teaching activities of the course. Transforming the knowledge input-oriented teaching method (teacher as the main body) into the knowledge output-oriented teaching method (student as the main body), making the dull teaching content relatively lively and interesting, effectively stimulating their learning enthusiasm and initiative, and improving the teaching quality and learning effect. In the process of teaching, we should not stick to a single teaching method, and adopt a combination of various teaching methods according to the teaching content, so as to make teaching "live" and students "move". Through questionnaires of course questionnaires and feedback questionnaires of course teaching information, we can timely understand students' learning dynamics and use various flexible teaching methods to assist teaching. In the environment designed by teachers, students constantly learn programming skills and gradually improve their ability of self-learning. After 
class, we implement the method of group cooperative learning to cultivate cooperative learning and communication among students. Ability to internalize what you have learned.

\section{E. Reforming the evaluation methods of examinations and construct the evaluation system of $N+2$ learning assessment}

In order to promote students' development, we adopt the whole process assessment model of $\mathrm{N}+2$ on computer, develop a computer program design language course examination system, strengthen students' application ability and innovation ability to solve practical problems in combination with their major through the process of performance evaluation, and track, rationalize and make the assessment process open and transparent.

The course nature of computer programming language course itself is to test the students' practical programming ability, while focusing on a single examination paper to determine the results of the examination method, it is easy for students to adopt the wrong learning method, memorize by rote, and strengthen memory in a short time, and do not really grasp and understand the basic programming methods and programming skills. We have developed the examination software of VB programming language, which pays attention to the examination points of students' application ability and innovation ability. We adopt the assessment mode of combining the process and finality of $\mathrm{N}+2 . \mathrm{N}$ is the number of module examinations. 2 is: 1 (normal performance) +1 (independent pre-school learning performance). Among them, 50 are normal + pre-school performance and 50 are module examinations. Total module score/ $\mathrm{N}$. The assessment mode of $\mathrm{N}+2$ on-line can promote students to study effectively, and strengthen students' application ability and innovation ability to solve practical problems in combination with their specialty. Taking VB programming as an example, the process assessment model is shown in Fig. 2.

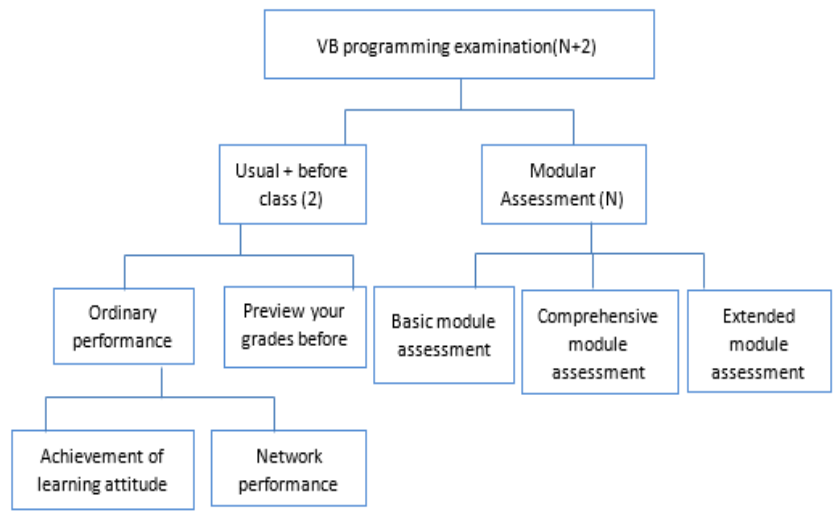

Fig. 2. VB Programming Process Assessment Model

\section{CONCLUSION}

We take vocational skills as the starting point and service specialty construction as the orientation to study the teaching of computer programming language courses for Applied Undergraduate students. We make full use of the advanced teaching ideas, flexible organization and resource sharing, and take the cultivation of applied talents as the ultimate goal to construct a reasonable teaching mode and method of computer language courses for public undergraduates.

With the development of Applied Undergraduate Education and the deepening of teaching reform, cultivating and strengthening the practical ability, autonomous learning ability and practical innovation ability of students of different majors are the key problems to be solved in Applied Undergraduate colleges. The teaching of public computer programming language is not only related to the cultivation of students' personal information literacy, but also to the cultivation of different majors. The plan of professional information knowledge talents has a certain impact. The applicationoriented undergraduate education is a pioneering and exploratory work. It must be realistic, pragmatic and keep pace with the times, and take a characteristic education path.

\section{REFERENCES}

[1] Lijuan Jiao, Suqin Feng. Discussion on the Teaching Reform of VB Programming [J]. Software Guide, No. 12, 2010(In Chinese)

[2] Tony Buzan, Translated by Li Si. Mind Mapping - Radioactive Thinking [M]. Beijing: World Book Publishing Company, 2004:59

[3] Rong Ding. Application of PBL in Programming Course [J]. Journal of Qinghai Teachers College, Educational Science. S3, 2005. (In Chinese) 